\title{
Liver resection versus transplantation for multiple hepatocellular carcinoma: a propensity score analysis
}

\author{
Chuan Li ${ }^{1}$, Jia-Ye Liu' ${ }^{1}$, Wei Peng ${ }^{1}$, Tian-Fu Wen ${ }^{1}$, Lu-Nan Yan ${ }^{1}$, Jia-Yin Yang ${ }^{1}$, Bo \\ $\mathbf{L i}^{1}$, Wen-Tao Wang ${ }^{1}$ and Ming-Qing $\mathbf{X u}^{1}$ \\ ${ }^{1}$ Department of Liver Surgery \& Liver Transplantation, West China Hospital of Sichuan University, Chengdu, China \\ Correspondence to: Tian- Fu Wen, email: aderwe@163.com \\ Keywords: liver transplantation, liver resection, hepatocellular carcinoma, outcomes, recurrence \\ Received: November 14,2016 Accepted: August 06, $2017 \quad$ Published: September 02, 2017
}

Copyright: Li et al. This is an open-access article distributed under the terms of the Creative Commons Attribution License 3.0 (CC BY 3.0), which permits unrestricted use, distribution, and reproduction in any medium, provided the original author and source are credited.

\section{ABSTRACT}

The aim of this study was to compare the outcomes of patients with multiple hepatocellular carcinoma (HCCs) after liver resection (LR) versus liver transplantation (LT). Patients who had multiple HCCs without macrovascular invasion and who underwent LT or LR between 2007 and 2013 were reviewed. A propensity score matching model was used to adjust baseline differences between the two groups. A total of 204 patients were selected for the current study, including 137 LR patients and 67 LT patients. During follow-up, 100 patients experienced recurrence, and 78 patients died. The 5-year recurrence-free survival rate was $71.1 \%$ for the LT group and $31.1 \%$ for the LR group $(P<0.001)$. The 5 -year overall survival rate was $73.4 \%$ for the LT group and $39.8 \%$ for the LR group $(P<0.001)$. Moreover, the LT group had better recurrence-free survival and overall survival rates than the LR group regardless of whether the patients met or exceeded the Milan criteria. The multivariate analysis showed that microvascular invasion and LR were independent risk factors for postoperative recurrence, whereas only LR was associated with an increased incidence of mortality. After applying one-to-one propensity score matching, similar results were observed in the propensity score matching model. Our study suggested that LT provided a better prognosis for patients with multiple HCCs than LR regardless of whether the patients met the Milan criteria.

\section{INTRODUCTION}

Hepatocellular carcinoma (HCC) is the sixth most common malignancy and the third leading cause of cancer-related death worldwide.[1] HCC is mainly associated with chronic hepatitis B virus (HBV) or hepatitis $\mathrm{C}$ virus (HCV) infection and accounts for approximately $6 \%$ of new cancer patients worldwide.[2,3] A seroepidemiological survey performed in 2006 showed that the hepatitis B surface antigen carrier rate was $7.18 \%$ in the overall Chinese population.[4] Due to this high prevalence, more than half of the HCC cases worldwide occur in China.[5] Many investigations have suggested that multiple HCCs contribute to a poorer prognosis than a single tumor.[6, 7] Liver resection and transplantation are two curative treatments for HCC. According to the Barcelona Clinic Liver Cancer (BCLC) staging system, both liver transplantation and resection are recommended for patients with multiple HCCs within the Milan criteria (i.e., a single tumor up to $5 \mathrm{~cm}$, up to 3 tumors with each tumor no larger than $3 \mathrm{~cm}$, and a lack of vascular invasion or extrahepatic metastasis). $[8,9]$ Although transcatheter arterial chemoembolization (TACE) is the standard treatment for patients with multiple HCCs outside of the Milan criteria, a number of studies have confirmed that these patients may also benefit from liver resection.[9-11] A randomized comparative trial performed by Lin et al[12] confirmed that overall survival following liver resection was superior to overall survival following TACE for patients with multiple HCCs outside of the Milan criteria. Moreover, some transplant selection criteria allow some patients with multiple HCCs beyond the Milan criteria (e.g., the up-to-seven criteria and the Hangzhou criteria) to undergo LT.[13, 14] However, whether LT or LR offer better outcomes for patients with multiple HCCs is unclear. 
The aim of this study is to clarify whether LT or LR is a better curative management practice for patients with multiple HCCs based on their recurrence-free and overall survival.

\section{PATIENTS AND METHODS}

\section{Study group}

Patients with multiple HCCs without macrovascular invasion who underwent LT or LR at our center between 2007 and 2013 were reviewed. Typically, both LR and LT are introduced to patients and/or their close relatives. The choice of treatment was dependent on many factors, including the patient's liver function, portal hypertension, the remnant liver volume, and especially the patient's preference. Currently, our medical insurance does not cover liver transplantation. Patients fulfilling the following criteria were excluded: underwent re-resection; positive surgical margin; presence of other tumor types; received dual graft liver transplantation; and underwent ABOincompatible liver transplantation. The patients were divided into LR and LT groups based on the treatment received. This study was approved by the ethics committee of West China Hospital.

\section{Surgical procedure}

For the patients who received LR, the liver was exposed via a right subcostal incision with an extension to the upper midline after general anesthesia. Intraoperative ultrasound was routinely used. Hemihepatic vascular occlusion or the Pringle maneuver was utilized to reduce intraoperative bleeding. A CUSA Excel ${ }^{\mathrm{TM}}$ device was used for liver transection. Drainage was routinely placed before closure. The donors were ABO blood type compatible and had negative laboratory findings. The donors for living donor liver transplantation (LDLT) were close relatives. Volumetric computed tomography with contrast was administered to evaluate the right hepatic lobes of all donors. The right hepatic lobes of donors without a middle hepatic vein were at least $0.8 \%$ of the recipient's weight, and the remaining liver remnant in the donor was at least $40 \%$ of the recipient's weight. For patients undergoing LT, the "Mercedes-Benz" incision was used. The liver grafts were preserved and flushed using the University of Wisconsin solution. A venous-venous bypass was not used in all liver transplantations.

\section{Follow-up}

After surgery, the patients were regularly followedup every three months and monitored using blood cell tests, liver function tests, serum alpha-fetoprotein (AFP) levels, visceral ultrasonography, either computed tomography or magnetic resonance imaging, and chest radiography. Postoperative recurrence was defined as either positive imaging findings compared with the preoperative examinations with or without newly rising tumor marker (AFP) values or confirmation by biopsy or resection.[14] The patients of the two groups were all followed up regularly until death or the termination of this study (September 2016).

\section{Immunosuppression and antiviral protocols}

Immunosuppressive maintenance comprised either tacrolimus or cyclosporine, mycophenolate mofetil, and a steroid after LT. Steroid pulse therapy was conducted in patients with rejection. Whenever possible, the steroid was tailed off as early as possible. For patients receiving LR, anti-viral treatment (entecavir or lamivudine) was administered to patients with a positive preoperative HBV DNA load. For patients who underwent LT, hepatitis B immune globulin was administered to the HBV patients before, during, and after transplantation. Lamivudine was also administered to the hepatitis B surface antigenpositive patients after LT.

\section{Statistical analysis}

All statistical analyses were performed using SPSS 22.0 for Windows. All continuous variables were presented as the mean $\pm \mathrm{SD}$ and compared using oneway analysis of variance. Categorical variables were compared using either the $\chi^{2}$ test or Fisher's exact test. The independent risk factors for recurrence-free survival (RFS) and overall survival (OS) were identified by Cox regression. The Kaplan-Meier method was used to compare the postoperative RFS and OS for the different groups. The differences in the RFS and OS curves were compared using a log-rank test. A P value less than 0.05 was considered significant.

To minimize the risk of selection bias, propensity score matching was used to balance the treatment choicerelated characteristics of the two groups. Then, the model was used to provide a one-to-one nearest-neighbor match between patients undergoing LR and LT.

\section{RESULTS}

\section{Baseline characteristics of the patient cohort}

A total of 216 patients were enrolled in the current study. Twelve patients were excluded due to loss of follow-up ( 9 patients in the LR group and 3 patients in 

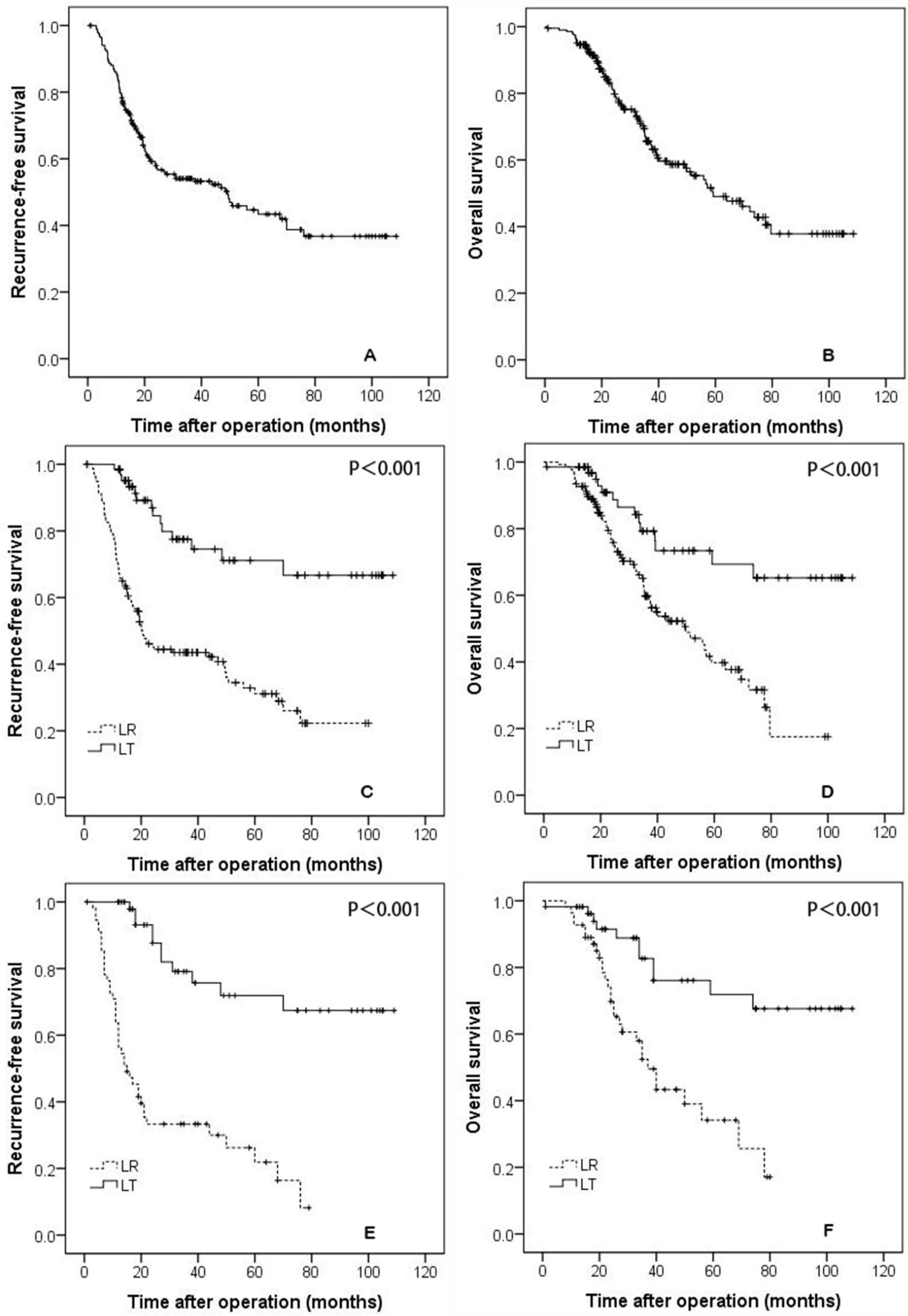

Figure 1: The recurrence-free A., and overall survival B., curves for all patients. The recurrence-free C., and overall survival D., rates for patients who underwent liver resection and transplantation. The recurrence-free E., and overall survival F., rates for propensity-matched patients who underwent liver resection and transplantation. 
Table 1: Clinicopathological characteristics of HCC patients before and after one-to-one propensity matching

\begin{tabular}{|l|c|c|c|c|c|c|}
\hline \multirow{2}{*}{ Variable } & \multicolumn{3}{c|}{ All patients } & \multicolumn{3}{c|}{ Propensity-matched patients } \\
\cline { 2 - 6 } & LR $(\boldsymbol{n}=\mathbf{1 3 7})$ & LT $(\boldsymbol{n}=\mathbf{6 7})$ & $\boldsymbol{n}$ & LR $(\boldsymbol{n}=\mathbf{5 5})$ & LT $(\boldsymbol{n}=\mathbf{5 5})$ & $\boldsymbol{P}$ \\
\hline Age $(\geq 60 /<60$ years) & $27 / 110$ & $7 / 60$ & 0.096 & $8 / 47$ & $6 / 49$ & 0.567 \\
\hline Female/male & $14 / 123$ & $6 / 61$ & 0.776 & $5 / 40$ & $6 / 49$ & 0.751 \\
\hline Total tumor size >5 cm & $92 / 45$ & $42 / 25$ & 0.528 & $38 / 17$ & $35 / 20$ & 0.545 \\
\hline No. of tumors >3 & $15 / 122$ & $16 / 51$ & 0.016 & $7 / 48$ & $7 / 48$ & 1.000 \\
\hline Milan criteria (yes/no) & $61 / 76$ & $31 / 36$ & 0.814 & $24 / 31$ & $24 / 31$ & 1.000 \\
\hline Differentiation (poor/well and moderate) & $31 / 106$ & $16 / 51$ & 0.842 & $13 / 42$ & $12 / 43$ & 0.820 \\
\hline MVI (positive/negative) & $44 / 93$ & $20 / 47$ & 0.743 & $15 / 40$ & $16 / 39$ & 0.832 \\
\hline AFP (>400/<400 ng/mL) & $52 / 85$ & $21 / 46$ & 0.355 & $20 / 35$ & $18 / 37$ & 0.688 \\
\hline HBV DNA load (positive/negative) & $57 / 80$ & $21 / 46$ & 0.157 & $20 / 35$ & $16 / 39$ & 0.416 \\
\hline BCLC stage A/B & $61 / 76$ & $31 / 36$ & 0.814 & $24 / 31$ & $24 / 31$ & 1.000 \\
\hline ECOG status (0/1) & $132 / 5$ & $61 / 6$ & 0.115 & $52 / 3$ & $51 / 4$ & 0.696 \\
\hline Child-Pugh status (A/B/C) & $137 / 0 / 0$ & $59 / 7 / 1$ & 0.001 & $55 / 0 / 0$ & $53 / 2 / 0$ & 0.154 \\
\hline
\end{tabular}

the LT group). Data from the remaining 204 patients were analyzed in this study. A total of 137 patients underwent LR and 67 patients received LT. Among the 67 LT patients, 16 patients received a living donor liver transplant and 51 patients underwent deceased donor liver transplantation. This study included 184 male patients and 20 female patients with a mean age of $49.70 \pm 11.19$ years. The mean total tumor size was $6.6 \pm 1.6 \mathrm{~cm}$, and 112 patients had multiple HCCs outside of the Milan criteria. A total of 73 patients had high preoperative AFP levels (defined as a preoperative AFP level greater than $400 \mathrm{ng} / \mathrm{mL}$ ).[14] HBV DNA was detected in 78 patients. Microvascular invasion (MVI) was observed in 64 patients, and 31 patients had more than 3 HCCs.

The mean follow-up time was $38.16 \pm 25.19$ months (median: 32.42 months). During the follow-up period, 100 patients experienced recurrence, and 78 patients died. The $1-, 3-$, and 5-year RFS rates for the whole study cohort were $78.2 \%, 54.1 \%$, and $43.4 \%$, respectively. The $1-, 3-$, and 5-year OS rates for all patients were 94.6\%, 65.6\%, and $49.0 \%$, respectively (Figure $1 \mathrm{~A}$ and $1 \mathrm{~B}$ ).

We compared the baseline characteristics of the two groups and found that the LT group had more patients with $>3$ tumors and more patients with Child-Pugh B and C statuses. There were no significant differences with respect to age, gender, MVI, and tumor size.

\section{Comparison of RFS and OS for all patients}

The 1-, 3-, and 5-year RFS rates were 98.5\%, 77.5\%, and $71.1 \%$ in the LT group and $68.6 \%, 43.5 \%$, and $31.1 \%$ in the LR group, respectively (Figure $1 \mathrm{C}, P<0.001$ ). The $1-, 3-$, and 5 -year OS rates of the LT group were $98.5 \%$, $79.3 \%$, and $73.4 \%$, respectively, and were significantly better than the rates of the LR group $(92.7 \%, 59.7 \%$, and $39.8 \%$, respectively, $P<0.001$; Figure 1D).

\section{Comparison of the RFS and OS for patients selected for the propensity model}

The baseline data for patients selected for the propensity model are shown in Table 1 delineated by group. The baseline characteristics of the two groups were similar in tumor size, tumor number, age, gender, MVI, and differentiation. Patients in the propensity model group undergoing LT had significantly better RFS and OS rates than the patients who received LR. The 1-, 3-, and 5-year RFS rates were $97.9 \%, 79.1 \%$, and $71.9 \%$ for the LT group and $70.9 \%, 41.5 \%$, and $21.9 \%$ for the LR group, respectively (Figure 1E, $P<0.001$ ). The 1-, 3-, and 5 -year OS rates were $98.2 \%, 82.7 \%$, and $71.8 \%$ for the LT group and $92.7 \%, 52.4 \%$, and $34.1 \%$ for the LR group, respectively (Figure 1F, $P<0.001$ ).

\section{Subgroup analysis based on the Milan criteria}

In this study, 92 patients with multiple HCCs fulfilled the Milan criteria, including 31 patients who underwent LT and 61 patients who received LR. For the patients with HCCs meeting the Milan criteria, the 1-, 3-, and 5-year RFS rates of the LT group were 100\%, 87.4\%, and $80.1 \%$, respectively, which were significantly better than the rates of the LR group $(68.9 \%, 48.4 \%$, and $38.6 \%$, respectively, $P<0.001$; Figure 1A). The 1-, 3-, and 5-year OS survival rates of the LT group $(100 \%, 91.1 \%$, and $85.4 \%$, respectively) patients who were within the Milan criteria were also better than the rates of the LR group patients $(93.4 \%, 63.1 \%$, and $51.2 \%$, respectively, $P=$ 0.006; Figure 2B).

In this study, 36 patients in the LT group and 76 patients in the LR group had multiple HCCs beyond the Milan criteria. For patients exceeding the Milan criteria, the 1-, 3-, and 5-year RFS rates of the LT group were $97.1 \%, 68.0 \%$, and $61.9 \%$, respectively, which were 
significantly better than the rates of the LR group (72.4\%, $39.7 \%$, and $24.8 \%$, respectively; $P=0.006$; Figure $2 \mathrm{C}$ ). The 1-, 3-, and 5-year OS survival rates were 97.2\%, $68.2 \%$, and $63.0 \%$, respectively, in the LT group and $92.1 \%, 57.7 \%$, and $31.6 \%$, respectively, in the LR group; the observed differences were significant $(P=0.040$; Figure 2D).

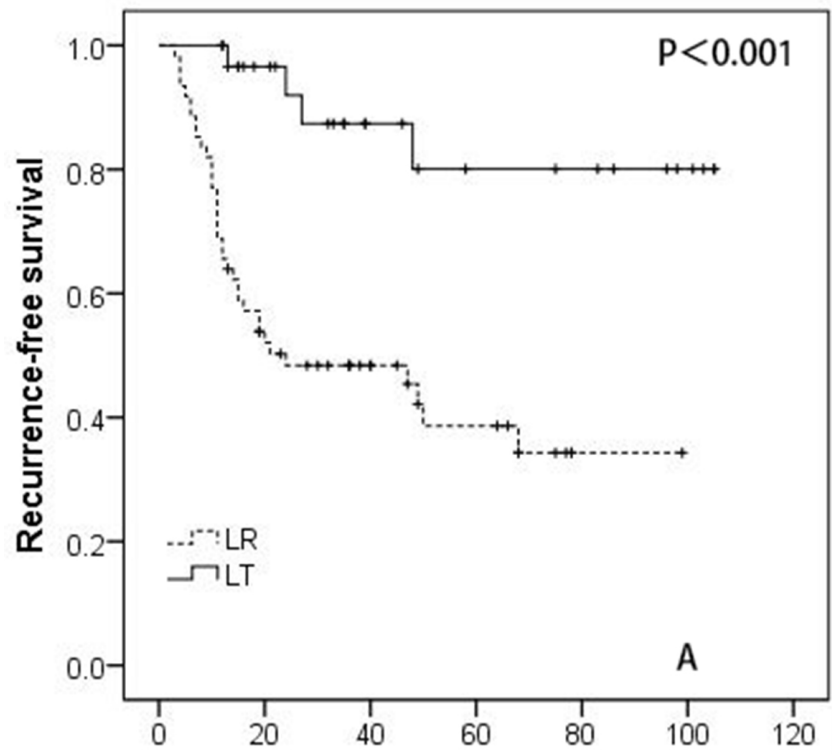

Time after operation (months)

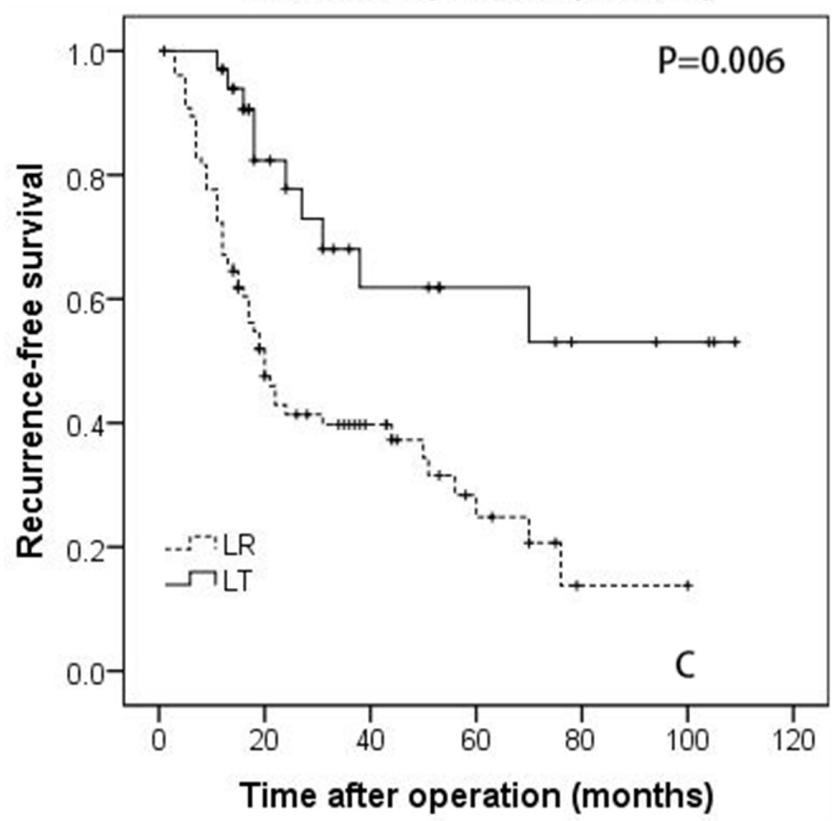

\section{Risk factor analysis for postoperative recurrence} and survival

As shown in Table 2, the univariate analysis suggested that the presence of MVI, a positive preoperative HBV DNA status, and LR were associated with high postoperative recurrence. However, the multivariate analysis for RFS in all patients suggested that $\mathrm{LR}(\mathrm{HR}=0.244,95 \% \mathrm{CI}=0.138-0.430)$ and MVI $(\mathrm{HR}$ $=1.599,95 \% \mathrm{CI}=1.069-2.392)$ were independent risk factors for postoperative recurrence.

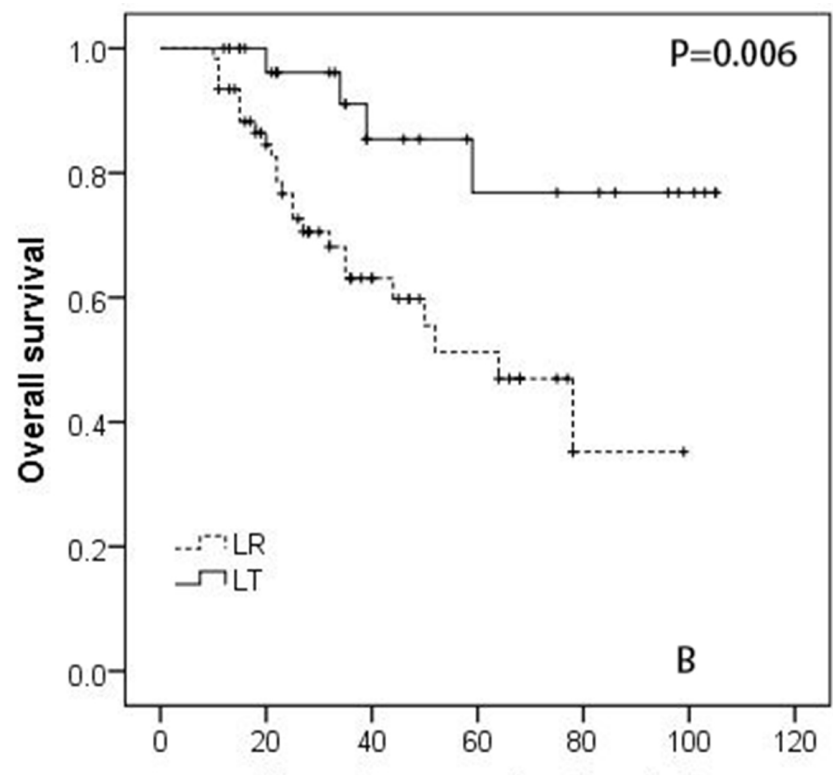

Time after operation (months)

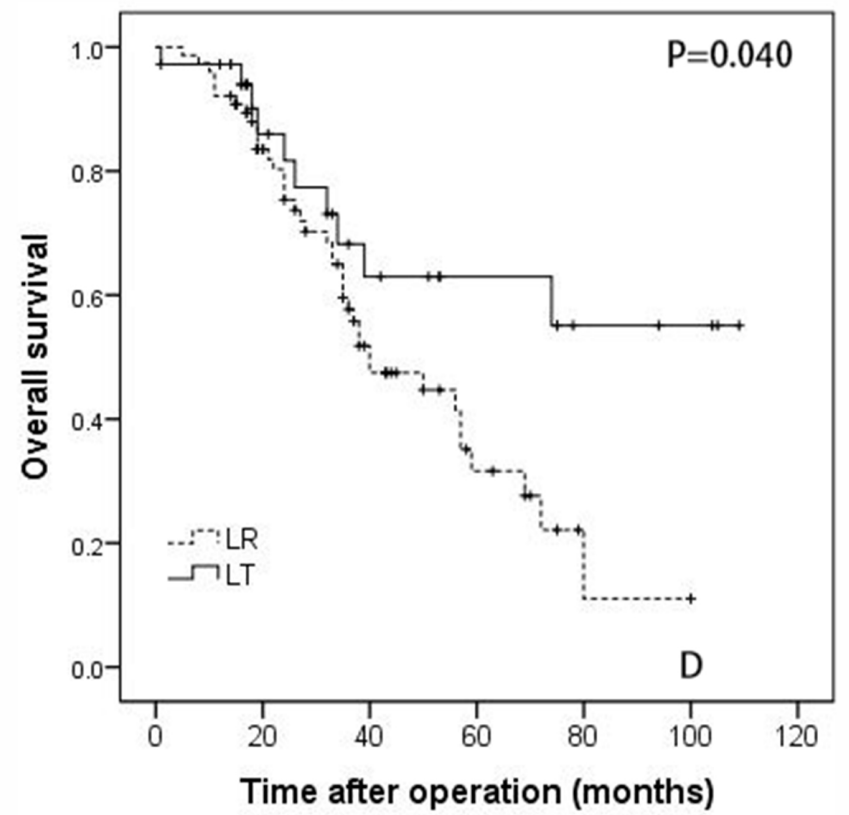

Figure 2: The recurrence-free A., and overall survival B. rates for patients with hepatocellular carcinoma within the Milan criteria who underwent liver resection and transplantation. The recurrence-free $\mathbf{C}$. and overall survival D. rates for patients with hepatocellular carcinoma beyond the Milan criteria who underwent liver resection and transplantation. 
Table 2: Univariate and multivariate analysis for RFS in patients with multiple HCCs undergoing LR or LT

\begin{tabular}{|c|c|c|c|c|c|c|c|}
\hline \multirow{2}{*}{ Variable } & \multirow{2}{*}{ Number } & \multicolumn{3}{|c|}{ Univariate analysis } & \multicolumn{3}{|c|}{ Multivariate analysis } \\
\hline & & HR & $95 \% \mathrm{CI}$ & $P$ & HR & $95 \% \mathrm{CI}$ & $P$ \\
\hline Age $(\geq 60 /<60$ years $)$ & $34 / 170$ & 1.048 & $0.502-2.189$ & 0.900 & & & \\
\hline Female/male & $20 / 184$ & 0.957 & $0.380-2.410$ & 0.926 & & & \\
\hline No. of tumors $(>3 / \leq 3)$ & $31 / 173$ & 1.401 & $0.647-3.035$ & 0.392 & & & \\
\hline Total tumor size $(>5 / \leq 5 \mathrm{~cm})$ & $134 / 70$ & 1.028 & $0.576-1.832$ & 0.926 & & & \\
\hline Milan criteria (yes/no) & $92 / 112$ & 1.625 & $0.932-2.835$ & 0.086 & & & \\
\hline MVI (yes/no) & $64 / 140$ & 2.020 & $1.105-3.693$ & 0.021 & 1.599 & $1.069-2.392$ & 0.022 \\
\hline $\operatorname{AFP}(>400 / \leq 400 \mathrm{ng} / \mathrm{mL})$ & $73 / 131$ & 0.935 & $0.527-1.658$ & 0.819 & & & \\
\hline HBV-DNA status (positive/negative) & $78 / 126$ & 1.917 & $1.081-3.399$ & 0.025 & & & 0.127 \\
\hline Differentiation (poor/well and moderate) & $47 / 157$ & 0.996 & $0.519-1.911$ & 0.990 & & & \\
\hline LR/LT & $67 / 137$ & 0.157 & $0.079-0.310$ & $<0.001$ & 0.244 & $0.138-0.430$ & $<0.001$ \\
\hline
\end{tabular}

Table 3: Univariate and multivariate analyses for OS in patients with multiple HCCs undergoing LR or LT

\begin{tabular}{|l|c|c|c|c|c|c|c|}
\hline \multirow{2}{*}{ Variable } & \multirow{2}{*}{ Number } & \multicolumn{3}{c|}{ Univariate analysis } & \multicolumn{3}{c|}{ Multivariate analysis } \\
\cline { 3 - 8 } & & HR & $\mathbf{9 5 \%}$ CI & $\boldsymbol{P}$ & HR & $\mathbf{9 5 \%}$ CI & $\boldsymbol{P}$ \\
\hline Age $(\geq 60 /<60$ years) & $34 / 170$ & 1.000 & $0.469-2.133$ & 1.000 & & & \\
\hline Female/male & $20 / 184$ & 0.586 & $0.232-1.480$ & 0.254 & & & \\
\hline No. of tumors $(>3 / \leq 3)$ & $31 / 173$ & 1.622 & $0.705-3.731$ & 0.252 & & & \\
\hline Total tumor size $(>5 / \leq 5 \mathrm{~cm})$ & $134 / 70$ & 1.178 & $0.647-2.144$ & 0.592 & & & \\
\hline Milan criteria (yes/no) & $92 / 112$ & 1.843 & $1.032-3.291$ & 0.038 & & & 0.054 \\
\hline MVI (yes/no) & $64 / 140$ & 1.400 & $0.766-2.558$ & 0.273 & & & \\
\hline AFP ( $>400 / \leq 400 \mathrm{ng} / \mathrm{mL})$ & $73 / 131$ & 0.698 & $0.383-1.272$ & 0.240 & & & \\
\hline HBV DNA status (positive/negative) & $78 / 126$ & 1.871 & $1.048-3.342$ & 0.033 & & & 0.174 \\
\hline Differentiation (poor/well and moderate) & $47 / 157$ & 1.127 & $0.579-2.194$ & 0.725 & & & \\
\hline LR/LT & $67 / 137$ & 0.301 & $0.153-0.593$ & $<0.001$ & 0.364 & $0.202-0.655$ & 0.001 \\
\hline
\end{tabular}

As presented in Table 3, the univariate analysis indicated that LR, a positive preoperative HBV DNA status, and failure to meet the Milan criteria were potential risk factors related to poor OS. However, in the Cox proportional hazards model, only LR $(\mathrm{HR}=0.364$, $95 \% \mathrm{CI}=0.202-0.655)$ was associated with an increased mortality rate.

\section{DISCUSSION}

HCC ranks as the third most frequent cancer-related death worldwide due to its aggressive nature.[1] Many studies have confirmed that multiple tumors are associated with an increased incidence of postoperative recurrence and a decreased survival rate.[6, 7] However, the optimal management strategy for patients with multiple HCCs is not well established. Our study suggested that liver transplantation provided better RFS and OS for patients with multiple HCCs without macrovascular invasion.

Multiple HCCs may be either intrahepatic metastasis from a primary HCC or multicentric in origin. $[15,16]$ Nagasue et al[17] suggested that multiple HCCs might all develop intrahepatic recurrence within 5 years after LR due to their multicentric origin. Many studies reported that the most common site for recurrence was the remaining liver.[16, 17] Some studies suggested that early recurrence (within the first 2 years after the operation) after liver resection might be metastasis arising from the primary $\mathrm{HCC}$, whereas late recurrence (more than 2 years after operation) might have a multicentric origin. $[18,19] \mathrm{Wu}$ and colleagues suggested that multiple HCCs were an independent risk factor for both early and late recurrence after liver resection. LT removes the entire affected liver and can eradicate micro-metastasis of the remaining liver. Moreover, LT not only removes the tumors but also cures any background liver diseases. In contrast, LR only resects the tumor and has no effect on background liver diseases.

Some investigations suggest that LR may offer longterm survival rates that are similar to the LT survival rates for patients with HCC within the Milan criteria.[20, 21] However, these studies included either solitary tumors up to $5 \mathrm{~cm}$ or no more than 3 tumors with each tumor no more than $3 \mathrm{~cm}$.[20, 21] In this study, we only included multiple tumors. We confirmed that the outcomes of patients with multiple HCCs who underwent LT were better than the outcomes of patients who underwent LR. Fan et al[22] confirmed that patients with a single tumor up to $5 \mathrm{~cm}$ had better 5-year survival rates than patients with polynodular tumors $(2-3$ nodules, each $\leq 3 \mathrm{~cm})$. Poon et al[23] also suggested that having multiple tumors was an independent risk factor associated with an increased recurrence rate and mortality for patients with HCC within the Milan criteria after liver resection or transplantation. 
TACE is the standard treatment for patients with multiple HCCs outside of the Milan criteria.[9] However, increasing evidence has shown that liver resection may provide a better prognosis for patients with multiple HCCs outside of the Milan criteria.[24, 25] A randomized comparative trial suggested that liver resection had better OS for patients with multiple HCCs outside of the Milan criteria than TACE.[12] A multicenter study also confirmed that patients with resectable HCC could benefit from LR over loco-regional therapy regardless of the cancer stage.[26] Recently, a systematic review and meta-analysis performed by Liu et al. confirmed that LR offered improved OS compared to TACE for patients with multiple HCCs beyond the Milan criteria.[27] A large systematic review and meta-analysis performed by Qi et al [28] also confirmed that LR provided better OS than TACE for patients with HCC. In Qi et al's subgroup meta-analysis, LR offered better OS for patients with HCC beyond BCLC stage A.[28] Moreover, some investigations suggested that LT could achieve outcomes for wellselected patients with HCC beyond the Milan criteria that were similar to the outcomes achieved with patients with HCC within the Milan criteria.[29] Our study suggested that LT offered better RFS and OS than liver resection for patients with multiple HCCs outside of the Milan criteria.

Our study suggested that MVI was associated with a high incidence of postoperative recurrence but not with OS. Previous studies confirmed that MVI was a strong prognostic factor for postoperative recurrence after either LR or LT.[22, 30] However, Shah et al [31] suggested that macrovascular invasion but not MVI was related to poor long-term survival after LT. The study performed by Vivarelli et al [32] also indicated that there was no relationship between postoperative OS and MVI for patients with HCC after LT. Moreover, Chan et al [33] reported that LT doubled the chances of a cured status for patients with HCC, with MVI, and within up-to-7 criteria compared with LR.

Although several published studies have compared the outcomes of LR versus LT for HCC, [23, 34-37] many of these studies focused on patients with early HCC.[23, 37] These studies also only included patients with single HCC.[23, 37] In contrast to these studies, our study only involved patients with multiple HCCs.

In conclusion, our study suggested that patients with multiple HCCs had better RFS and OS following liver transplantation compared with liver resection regardless of whether they met or exceeded the Milan criteria.

\section{Abbreviations}

alpha-fetoprotein (AFP); Barcelona Clinic Liver Cancer (BCLC); hepatitis B virus (HBV); hepatitis C virus (HCV); hepatocellular carcinoma (HCC); liver resection (LR); liver transplantation (LT); propensity score matching model (PSM model); transcatheter arterial chemoembolization (TACE).

\section{Author contribution}

Li C and Wen TF proposed this study. Li C, Liu JY, and Peng $\mathrm{W}$ collected the data. Li C analyzed the data. Yan LN, Yang JY, Li B, Wang WT, and Xu MQ contributed to the execution and discussion.

\section{ACKNOWLEDGMENTS}

This study was supported by grants from the National Science and Technology Major Project of China (2012ZX10002-016 and 2012ZX10002-017), as well as the Scientific and Technological Support Project of Sichuan Province (2016SZ0025 and 2015SZ0049).

\section{CONFLICTS OF INTEREST}

The authors declared no conflict of interest

\section{REFERENCES}

1. Fattovich G, Bortolotti F, Donato F. Natural history of chronic hepatitis B: special emphasis on disease progression and prognostic factors. J Hepatol. 2008; 48:335-352.

2. El-Serag HB. Epidemiology of viral hepatitis and hepatocellular carcinoma. Gastroenterology. 2012; 142:1264-1273.e1.

3. Anfuso B, El-Khobar KE, Sukowati CH, Tiribelli C. The multiple origin of cancer stem cells in hepatocellular carcinoma. Clin Res Hepatol Gastroenterol. 2015; 39:S9297.

4. Cui Y, Jia J. Update on epidemiology of hepatitis B and C in China. J Gastroenterol Hepatol. 2013; 28:7-10.

5. Parkin DM, Bray F, Ferlay J, Pisani P. Global cancer statistics, 2002. CA Cancer J Clin. 2005; 55:74-108.

6. Liu W, Wang K, Bao Q, Sun Y, Xing BC. Hepatic resection provided long-term survival for patients with intermediate and advanced-stage resectable hepatocellular carcinoma. World J Surg Oncol. 2016; 14:62.

7. Belghiti J, Kianmanesh R. Surgical treatment of hepatocellular carcinoma. HPB (Oxford). 2005; 7:42-49.

8. Mazzaferro V, Regalia E, Doci R, Andreola S, Pulvirenti A, Bozzetti F, Montalto F, Ammatuna M, Morabito A, Gennari L. Liver transplantation for the treatment of small hepatocellular carcinomas in patients with cirrhosis. N Engl J Med. 1996; 334:693-699.

9. Bruix J, Reig M, Sherman M. Evidence-Based Diagnosis, Staging, and Treatment of Patients With Hepatocellular Carcinoma. Gastroenterology. 2016; 150:835-853. 
10. Dong ZR, Zhang PF, Wang CH, Zhang C, Cai JB, Shi GM, Ke AW, Sun HC, Qiu SJ, Zhou J, Fan J. Postoperative adjuvant transcatheter arterial chemoembolization for resectable multiple hepatocellular carcinoma beyond the Milan criteria: a retrospective analysis. Am J Cancer Res. 2015; 5:450-457.

11. Hsu CY, Liu PH, Hsia CY, Lee YH, Nagaria TS, Lee RC, Lin HC, Huo TI. Surgical Resection is Better than Transarterial Chemoembolization for Patients with Hepatocellular Carcinoma Beyond the Milan Criteria: A Prognostic Nomogram Study. Ann Surg Oncol. 2016; 23:994-1002.

12. Yin L, Li H, Li AJ, Lau WY, Pan ZY, Lai EC, Wu MC, Zhou WP. Partial hepatectomy vs. transcatheter arterial chemoembolization for resectable multiple hepatocellular carcinoma beyond Milan Criteria: a RCT. J Hepatol. 2014; 61:82-88.

13. Mazzaferro V, Llovet JM, Miceli R, Bhoori S, Schiavo M, Mariani L, Camerini T, Roayaie S, Schwartz ME, Grazi GL, Adam R, Neuhaus P, Salizzoni M, et al. Predicting survival after liver transplantation in patients with hepatocellular carcinoma beyond the Milan criteria: a retrospective, exploratory analysis. Lancet Oncol. 2009; 10:35-43.

14. Zheng SS, Xu X, Wu J, Chen J, Wang WL, Zhang M, Liang TB, Wu LM. Liver transplantation for hepatocellular carcinoma: Hangzhou experiences. Transplantation. 2008; 85:1726-1732.

15. Feo F, Pascale RM. Multifocal hepatocellular carcinoma: intrahepatic metastasis or multicentric carcinogenesis? Ann Transl Med. 2015; 3:4.

16. Schwartz M, Roayaie S, Konstadoulakis M. Strategies for the management of hepatocellular carcinoma. Nat Clin Pract Oncol. 2007; 4:424-432.

17. Nagasue N, Uchida M, Makino Y, Takemoto Y, Yamanoi A, Hayashi T, Chang YC, Kohno H, Nakamura T, Yukaya $\mathrm{H}$. Incidence and factors associated with intrahepatic recurrence following resection of hepatocellular carcinoma. Gastroenterology. 1993; 105:488-494.

18. Dekervel J, Popovic D, van Malenstein H, Windmolders P, Heylen L, Libbrecht L, Bulle A, De Moor B, Van Cutsem E, Nevens F, Verslype C, van Pelt J. A Global Risk Score (GRS) to Simultaneously Predict Early and Late Tumor Recurrence Risk after Resection of Hepatocellular Carcinoma. Transl Oncol. 2016; 9:139-146.

19. Sohn W, Paik YH, Kim JM, Kwon CH, Joh JW, Cho JY, Gwak GY, Choi MS, Lee JH, Koh KC, Paik SW, Yoo BC. HBV DNA and HBsAg levels as risk predictors of early and late recurrence after curative resection of HBV-related hepatocellular carcinoma. Ann Surg Oncol. 2014; 21:24292435.

20. Facciuto ME, Rochon C, Pandey M, Rodriguez-Davalos M, Samaniego S, Wolf DC, Kim-Schluger L, Rozenblit G, Sheiner PA. Surgical dilemma: liver resection or liver transplantation for hepatocellular carcinoma and cirrhosis. Intention-to-treat analysis in patients within and outwith
Milan criteria. HPB (Oxford). 2009; 11:398-404.

21. Silva MF, Sapisochin G, Strasser SI, Hewa-Geeganage S, Chen J, Wigg AJ, Jones R, Saraiva R, Kikuchi L, Carrilho F, Fontes PR, Charco R. Liver resection and transplantation offer similar 5-year survival for Child-PughTurcotte A HCC-patients with a single nodule up to $5 \mathrm{~cm}$ : a multicenter, exploratory analysis. Eur J Surg Oncol. 2013; 39:386-395.

22. Fan ST, Poon RT, Yeung C, Lam CM, Lo CM, Yuen WK, Ng KK, Liu CL, Chan SC. Outcome after partial hepatectomy for hepatocellular cancer within the Milan criteria. Br J Surg. 2011; 98:1292-1300.

23. Poon RT, Fan ST, Lo CM, Liu CL, Wong J. Difference in tumor invasiveness in cirrhotic patients with hepatocellular carcinoma fulfilling the Milan criteria treated by resection and transplantation: impact on long-term survival. Ann Surg. 2007; 245:51-58.

24. Hsu CY, Hsia CY, Huang YH, Su CW, Lin HC, Pai JT, Loong CC, Chiou YY, Lee RC, Lee FY, Huo TI, Lee $\mathrm{SD}$. Comparison of surgical resection and transarterial chemoembolization for hepatocellular carcinoma beyond the Milan criteria: a propensity score analysis. Ann Surg Oncol. 2012; 19:842-849.

25. Liu PH, Lee YH, Hsu CY, Hsia CY, Huang YH, Chiou YY, Lin HC, Huo TI. Surgical resection is better than transarterial chemoembolization for hepatocellular carcinoma beyond Milan criteria independent of performance status. J Gastrointest Surg. 2014; 18:16231631.

26. Vitale A, Burra P, Frigo AC, Trevisani F, Farinati F, Spolverato G, Volk M, Giannini EG, Ciccarese F, Piscaglia F, Rapaccini GL, Di Marco M, Caturelli E, et al. Survival benefit of liver resection for patients with hepatocellular carcinoma across different Barcelona Clinic Liver Cancer stages: a multicentre study. J Hepatol. 2015; 62:617-624.

27. Liu W, Zhou JG, Sun Y, Zhang L, Xing BC. Hepatic Resection Improved the Long-Term Survival of Patients with BCLC Stage B Hepatocellular Carcinoma in Asia: a Systematic Review and Meta-Analysis. J Gastrointest Surg. 2015; 19:1271-1280.

28. Qi X, Wang D, Su C, Li H, Guo X. Hepatic resection versus transarterial chemoembolization for the initial treatment of hepatocellular carcinoma: A systematic review and meta-analysis. Oncotarget. 2015; 6:18715-33. https://doi. org/10.18632/oncotarget.4134.

29. Xu X, Lu D, Ling Q, Wei X, Wu J, Zhou L, Yan S, Wu L, Geng L, Ke Q, Gao F, Tu Z, Wang W, et al. Liver transplantation for hepatocellular carcinoma beyond the Milan criteria. Gut. 2016; 65:1035-1041.

30. Agopian VG, Harlander-Locke M, Zarrinpar A, Kaldas FM, Farmer DG, Yersiz H, Finn RS, Tong M, Hiatt JR, Busuttil RW. A novel prognostic nomogram accurately predicts hepatocellular carcinoma recurrence after liver transplantation: analysis of 865 consecutive liver transplant recipients. J Am Coll Surg. 2015; 220:416-427. 
31. Shah SA, Tan JC, McGilvray ID, Cattral MS, Levy GA, Greig PD, Grant DR. Does microvascular invasion affect outcomes after liver transplantation for HCC? A histopathological analysis of 155 consecutive explants. J Gastrointest Surg. 2007; 11:464-471.

32. Vivarelli M, Cucchetti A, Piscaglia F, La Barba G, Bolondi L, Cavallari A, Pinna AD. Analysis of risk factors for tumor recurrence after liver transplantation for hepatocellular carcinoma: key role of immunosuppression. Liver Transpl. 2005; 11:497-503.

33. Chan SC, Fan ST, Chok KS, Cheung TT, Chan AC, Fung JY, Poon RT, Lo CM. Survival advantage of primary liver transplantation for hepatocellular carcinoma within the upto-7 criteria with microvascular invasion. Hepatol Int. 2012; 6:646-656.

34. Qi X, Zhao Y, Li H, Guo X, Han G. Management of hepatocellular carcinoma: an overview of major findings from meta-analyses. Oncotarget. 2016; 7:34703-51. https:// doi.org/10.18632/oncotarget.9157.
35. Lin J, Wu L, Bai X, Xie Y, Wang A, Zhang H, Yang X, Wan X, Lu X, Sang X, Zhao H. Combination treatment including targeted therapy for advanced hepatocellular carcinoma. Oncotarget. 2016; 7:71036-51. https://doi. org/10.18632/oncotarget.11954.

36. Xu XS, Liu C, Qu K, Song YZ, Zhang P, Zhang YL. Liver transplantation versus liver resection for hepatocellular carcinoma: a meta-analysis. Hepatobiliary Pancreat Dis Int. 2014; 13:234-241.

37. Shah SA, Cleary SP, Tan JC, Wei AC, Gallinger S, Grant DR, Greig PD. An analysis of resection vs transplantation for early hepatocellular carcinoma: defining the optimal therapy at a single institution. Ann Surg Oncol. 2007; 14:2608-2614. 